\title{
Simultaneous Determination of Enantiomers of Structurally Related Anticholinergic Analogs in Human Serum by Liquid Chromatography-Electrospray Ionization Mass Spectrometry with On-Line Sample Cleanup
}

Vladimír Čápka

Cleveland State University

Yan Xu

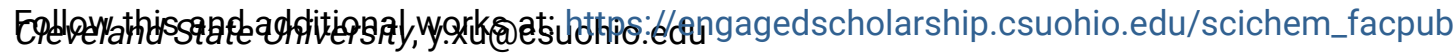

Part of the Analytical Chemistry Commons

How does access to this work benefit you? Let us know!

\section{Publisher's Statement}

NOTICE: this is the author's version of a work that was accepted for publication in Journal of Chromatography B: Biomedical Sciences and Applications. Changes resulting from the publishing process, such as peer review, editing, corrections, structural formatting, and other quality control mechanisms may not be reflected in this document. Changes may have been made to this work since it was submitted for publication. A definitive version was subsequently published in Journal of Chromatography B: Biomedical Sciences and Applications, 762, 2, October 25, 2001. DOI\#10.1016/S0378-4347(01)00364-4

\section{Recommended Citation}

Čápka, Vladimír and Xu, Yan, "Simultaneous Determination of Enantiomers of Structurally Related Anticholinergic Analogs in Human Serum by Liquid Chromatography-Electrospray lonization Mass Spectrometry with On-Line Sample Cleanup" (2001). Chemistry Faculty Publications. 212. https://engagedscholarship.csuohio.edu/scichem_facpub/212 


\title{
Simultaneous determination of enantiomers of structurally related anticholinergic analogs in human serum by liquid chromatography- electrospray ionization mass spectrometry with on-line sample cleanup
}

\author{
Vladimír Čápk , Yan X
}

\section{Introduction}

Trihexyphenidyl (THP), procyclidine and biperiden (Fig. 1) are anticholinergic drugs administered as racemates for the treatment of Parkinson's disease and extrapyramidal side effects of neuroleptics [1-4]. Anticholinergic drugs compete with the neurotransmitter acetylcholine for its receptor sites at synaptic junctions, which consequently leads to inhibition of transmission of certain nerve impulses. Side effects of THP include bradycardia, disturbances of recent memory, and myasthenia gravis. Among psychotic patients, it demonstrated hallucinogenic and euphoric properties that led to its frequent abuse either alone or in the combination with other opiates and narcotics [5]. Other side effects of common anticholinergic drugs include blurred vision, constipation, dryness of the mouth, mental disturbances, slurred speech, and urinary urgency or retention [6]. Understanding the clinical pharmacology of these drugs is the first step toward the elimination of these adverse side effects.

It has been long recognized that receptor-binding 


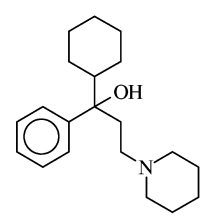

trihexyphenidyl MW $=301$

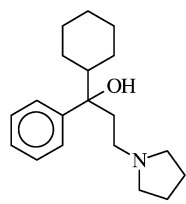

procyclidine $\mathrm{MW}=287$

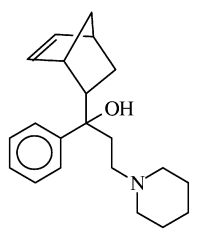

biperiden $\mathrm{MW}=311$

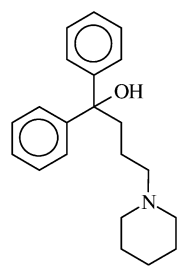

diphenidol (I.S.)

Fig. 1. Chemical structures of trihexyphenidyl, procyclidine, biperiden and diphenidol (I.S.).

sites in biological systems are often asymmetrical and therefore capable of discriminating between optical isomers of chiral drugs [7]. Consequently, two enantiomers of a racemic drug may have different pathways of their absorption, distribution, and metabolism in human body. Hence, these enantiomers can have different activity and toxicity in the body. It is not unusual in clinical pharmacology that one enantiomer of a drug is more potent than the other, or one has a therapeutic effect whereas the other has serious adverse drug reactions [8]. It was indicated by previously published studies [7,9-15] that $(R)$-enantiomers of THP and procyclidine have significantly higher affinities for muscarinic receptor subtypes than the corresponding $(S)$-enantiomers, and the binding patterns of their $(R)$ - and $(S)$-enantiomers are different. In case of biperiden, it was shown that $(+)$-enantiomer was able to differentiate at least three populations of muscarinic receptor subtypes whereas (-)-enantiomer was nearly devoid of such selectivity [16]. However, these studies showed no conclusions about the potency of the "high affinity" enantiomer because no correlation was observed between its potency and the affinity ratios of the two enantiomers [7,10]. This situation was in part due to the lack of sensitive stereoselective analytical methodology for the determination of these enantiomers in biological fluids.

In this work, we present an analytical method for the simultaneous determination of enantiomers of THP, procyclidine and biperiden in human serum by liquid chromatography-electrospray ionization mass spectrometry (LC-ESI-MS) with on-line sample extraction. The method employs a column-switching technique [17-24] to streamline the on-line sample preparation with LC-ESI-MS chiral analysis. Online sample preparation is accomplished using a "semi-permeable surface" (SPS) $\mathrm{C}_{18}$ cartridge column for exclusion of serum proteins and retention of drug molecules. The elution of drugs to LC-ESI-MS system is accomplished by changing elution strength of the mobile phase. The drug molecules are then separated on a $\beta$-cyclodextrin $(\beta-C D)$ column into their individual enantiomers based on the improvement of our recent work [25]. Quantitation is done by ESI-MS in the selected ion monitoring (SIM) mode. The entire analysis can be automated and requires little operator skill. We believe that the method developed provides a useful analytical method for the determination of enantiomers of THP, procyclidine, and biperiden in human serum. It can be used in pharmacological, forensic and toxicological studies where the simultaneous determination of multi-drug mixtures is required.

\section{Experimental}

\section{Materials}

DL-Trihexyphenidyl hydrochloride, DL-procyclidine hydrochloride, diphenidol hydrochloride, ammonium acetate $(>98 \%)$, acetonitrilie (HPLC grade) and methanol (HPLC grade) were from Sigma (St. Louis, MO, USA). Glacial acetic acid (HPLC grade) was from J.T. Baker (Phillipsburgh, NJ, USA). Triethylamine (TEA, >99\%) was from Aldrich (Milwaukee, WI, USA). DL-Biperiden hydrochloride was donated by Knoll Pharmaceutical (Mount Olive, 
NJ, USA). Control human serum (catalog No. 2930149) was from ICN (Costa Mesa, CA, USA).

Deionized water was obtained from a NANOpure water system (Branstead/Thermolyne, Dubuque, IA, USA). Standard aqueous solutions of procyclidine, THP, biperiden, and diphenidol were prepared by dissolving appropriate amounts of solid compounds in deionized water and serially diluting the resulting solutions with deionized water. Standard solutions for chiral separation optimization were prepared by dissolving appropriate amounts of solid compounds in the analytical column mobile phase and appropriate dilutions of the resulting solutions with the analytical column mobile phase.

In this work, the analytical column mobile phase was filtered through a Fluoropore PTFE membrane (type $\mathrm{FH}, 0.5-\mu \mathrm{m}$ pore) filter (Millipore, Bedford, MA, USA) prior to use. Standard solutions prepared in the analytical column mobile phase were filtered through Whatman nylon syringe filters (sterile, 4 $\mathrm{mm}, 0.2-\mu \mathrm{m}$ pore) from Fisher (Itasca, IL, USA). All serum and aqueous solutions were filtered through Corning cellulose acetate syringe filters (sterile, 47 $\mathrm{mm}, 0.45 \mu \mathrm{m}$ pore) from Fisher as well.

\section{Instrumentation}

The column-switching setup used for this work is schematically shown in Fig. 2. It included two HPLC systems (one for on-line sample extraction, and the other for chiral separation and detection). These systems were connected via a Rheodyne 7000 twoposition six-port switching valve (Supelco, Bellefonte, PA, USA). The on-line sample extraction system consisted of a GP 40 gradient LC pump (Dionex, Sunnyvale, CA, USA), a HP 1100 autosampler (Hewlett-Packard, San Fernando, CA, USA), and an SPS pre-column $\left(\mathrm{C}_{18}, 10 \times 3.0 \mathrm{~mm}\right.$, Regis

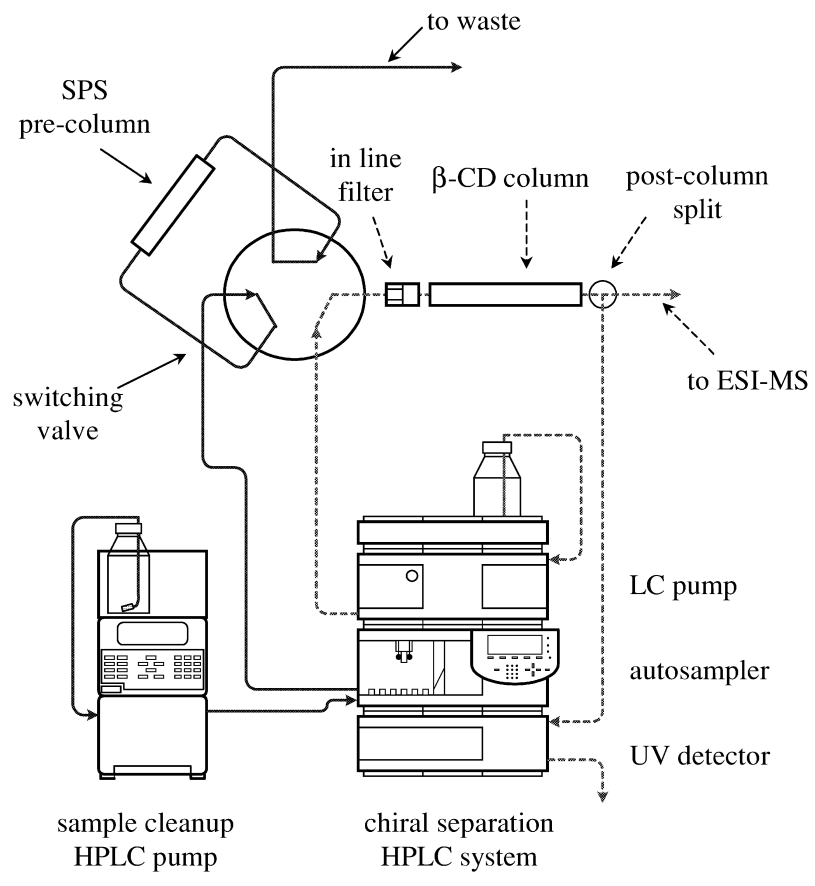

position A

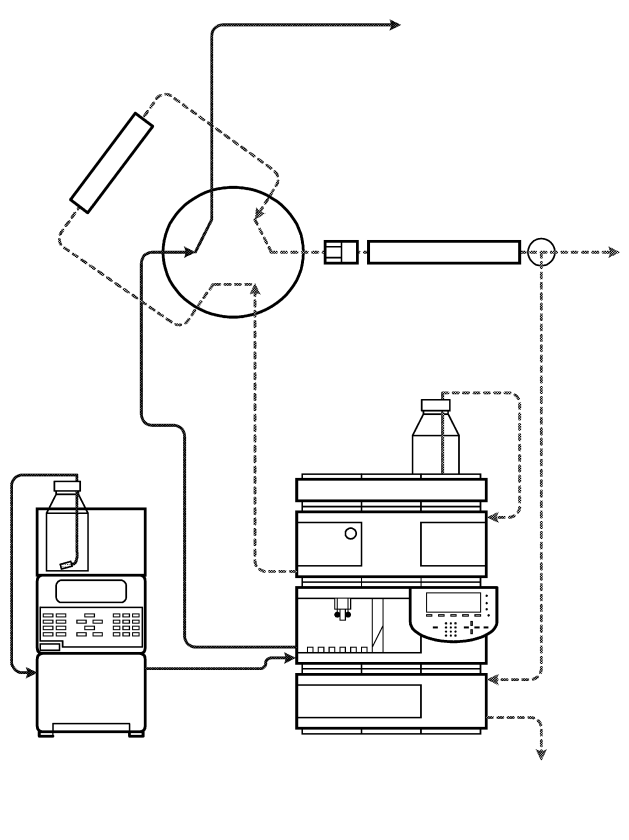

position B

Fig. 2. Schematic diagram of the column-switching setup. Position A: on-line sample extraction; position B: chiral separation and MS detection. Solid line, the flow path of the extraction mobile phase $\left(0.05 \mathrm{M} \mathrm{N \textrm {N } _ { 4 }}\right.$ Ac in $10 \% \mathrm{CH}_{3} \mathrm{CN}$ in water, $\left.1.0 \mathrm{ml} / \mathrm{min}\right)$. Dashed line, the flow path of the LC-MS mobile phase $\left(\mathrm{CH}_{3} \mathrm{CN}-\mathrm{CH}_{3} \mathrm{OH}-\mathrm{HAc}-\mathrm{TEA}, 95: 5: 0.5: 0.3, \mathrm{v} / \mathrm{v}, 0.25 \mathrm{ml} / \mathrm{min}\right)$. 
Technologies, Morton Grove, IL, USA). The LCMS (UV) system used for chiral separation and detection consisted of a HP 1100 binary LC gradient pump, a HP 1100 variable-wavelength UV detector, a Cyclobond I 2000 native $\beta-C D$ phase analytical column $(250 \times 2.0 \mathrm{~mm}$, Advanced Separation Technologies, Whippany, NJ, USA), an ultra-low dead volume stainless steel in-line filter $(0.5-\mu \mathrm{m}$ pore, 0.23- $\mu$ l dead volume, Upchurch Scientific, Oak Harbor, WA, USA), and a Quattro II triple quadrupole mass spectrometer with a MassLynx data acquisition system from Micromass (Manchester, UK).

The connection of the analytical column to the MS detector was via a Valco (Houston, TX, USA) stainless steel splitting tee $(1 / 16 \mathrm{in} . \times 0.25 \mathrm{~mm}$; 1 in. $=2.54 \mathrm{~cm}$ ) at a post-column split ratio of $1: 8$. The split ratio was adjusted by the resistance of the two outgoing lines with the smaller flow connected to the MS detector and the larger one to the UV detector. For all the connections, high-pressure polyether ether ketone (PEEK) tubing (1/16 in. O.D.) was used. 0.01 in. I.D. tubing was used for the on-line sample extraction system, and 0.005 in. I.D. for the LC-MS system.

\section{On-line sample extraction and LC chiral separation}

An SPS pre-column was used for the on-line sample extraction. Human serum containing DL-trihexyphenidyl hydrochloride, DL-biperiden hydrochloride, DL-procyclidine hydrochloride, and diphenidol hydrochloride (internal standard, I.S.) or an aqueous mixture of the standard solutions was first filtered using a cellulose-acetate syringe filter. Then, a 50- $\mu$ l portion of the sample was injected by the autosampler onto the SPS pre-column with a mobile phase of $0.05 \mathrm{M} \mathrm{NH}_{4} \mathrm{Ac}(\mathrm{pH} 6.98)$ in $10 \%(\mathrm{v} / \mathrm{v})$ $\mathrm{CH}_{3} \mathrm{CN}$ at a flow-rate of $1 \mathrm{ml} / \mathrm{min}$, and the switching valve in position A (Fig. 2). After 4-min sample extraction and cleanup, the mobile phase was changed to $\mathrm{CH}_{3} \mathrm{CN}-\mathrm{CH}_{3} \mathrm{OH}-\mathrm{HAc}-\mathrm{TEA}$ (95:5: $0.5: 0.3, \mathrm{v} / \mathrm{v})$, and the flow-rate was reduced to 0.25 $\mathrm{ml} / \mathrm{min}$ by switching the valve to the position $\mathrm{B}$ (Fig. 2). The drugs and the internal standard were eluted from the pre-column and separated in the $\beta-C D$ analytical column by the same mobile phase.
The valve was switched back to the position A at 15 min after the injection, and the pre-column was equilibrated by pumping the mobile phase of $0.05 \mathrm{M}$ $\mathrm{NH}_{4} \mathrm{Ac}\left(\mathrm{pH}\right.$ 6.98) in $10 \%(\mathrm{v} / \mathrm{v}) \mathrm{CH}_{3} \mathrm{CN}$ at a flowrate of $1 \mathrm{ml} / \mathrm{min}$ until the next injection.

\section{ESI-MS detection}

The MS detector was operated in the positive electrospray ionization (ESI+) mode. It was tuned by infusion of a mixture of analytes in analytical column mobile phase (at $170 \mu \mathrm{g} / \mathrm{ml}$ for THP, 167 $\mu \mathrm{g} / \mathrm{ml}$ for procyclidine, $167 \mu \mathrm{g} / \mathrm{ml}$ for biperiden, and $84 \mu \mathrm{g} / \mathrm{ml}$ for diphenidol) with a Harvard syringe pump (Harvard Apparatus, South Natick, MA, USA) at a flow-rate of $3 \mu \mathrm{l} / \mathrm{min}$ via a $75-\mathrm{mm}$ I.D. fused-silica capillary. The ionization conditions were: nitrogen desolvation gas at $300 \mathrm{l} / \mathrm{h}$, capillary at $3.00 \mathrm{kV}$, cone at $-40 \mathrm{~V}$, skimmer at $5 \mathrm{~V}$, radio frequency (RF) lens at $0.5 \mathrm{~V}$, ion source temperature at $70^{\circ} \mathrm{C}$, low- and high-mass resolution at 15 , ion energy at $1.6 \mathrm{~V}$, and photomultiplier at $-650 \mathrm{~V}$.

Full scan spectra were acquired in the continuum mode over the mass range of 200-400 $u$ at the scan speed of $200 \mathrm{u} / \mathrm{s}$. Selected-ion monitoring (SIM) mode was used for quantitation by sequentially monitoring quasi-molecular ions of each analyte $(\mathrm{m} /$

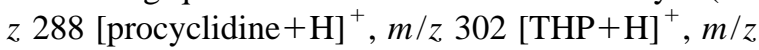
310 [I.S. $+\mathrm{H}]^{+}$, and $m / z 312$ [biperiden $\left.+\mathrm{H}\right]^{+}$). Data acquisition was done with a dwell time of $0.5 \mathrm{~s}$, one replicate for each data point, and an inter-scan delay of $0.02 \mathrm{~s}$. Ionization parameters used were the same as those described above.

The MS-MS detection mode (MRM) was also examined. The MRM data acquisition was based on mass fragmentation reactions of each parent ion (e.g., $\mathrm{m} / \mathrm{z} 288$ for procyclidine, $\mathrm{m} / \mathrm{z} 302$ for THP, $\mathrm{m} / \mathrm{z} 310$ for the I.S., and $m / z 312$ for biperiden). The ionization conditions of MRM mode were the same as those used in SIM data acquisition mode (see earlier). In order to find appropriate mass fragmentation reactions, daughter spectra were acquired in continuum mode over the mass range of 50-350 u with the scan speed of $300 \mathrm{u} / \mathrm{s}$. The low- and high-mass resolution was 10 for the first quadrupole and 15 for the third. The collision gas was Ar at a pressure of $2.6 \cdot 10^{-3}$ mbar. The resulting spectra were averaged over 2-min time windows. The MRM 
data acquisition was done with the dwell time of 0.5 $\mathrm{s}$, inter-scan delay time of $0.02 \mathrm{~s}$, and collision energy of $20 \mathrm{eV}$ for each acquisition function. Mass fragmentation reactions used for MRM data acquisition were $\mathrm{m} / \mathrm{z} \quad 288 \rightarrow \mathrm{m} / \mathrm{z} 84$ for procyclidine, $\mathrm{m} / \mathrm{z}$ $302 \rightarrow m / z \quad 98$ for THP, $m / z \quad 310 \rightarrow m / z, 129$ for the I.S., and $m / z \quad 312 \rightarrow m / z, 98$ for biperiden.

\section{Preparation of samples and standard serum solutions}

Serum standard and sample solutions were prepared by spiking the mixed aqueous analyte standards to the blank human serum and subsequent serial dilutions with blank human serum. Final serum solutions were spiked with I.S aqueous solution in the ratio of 20/1 (serum/I.S. solution) to produce 50 $\mathrm{ng} / \mathrm{ml}$ concentration of I.S. in serum. Each serum sample/standard contained at least $95 \%$ of serum matrix. After vortex-mixing, each serum solution was filtered through a cellulose acetate syringe filter (sterile, $47 \mathrm{~mm}, 0.45 \mu \mathrm{m}$ pore) and transferred to an autosampler vial.

\section{Results and discussion}

\section{On-line sample cleanup}

An SPS pre-column $[16,18,24]$ was chosen in this work for on-line sample cleanup based on the structures and polarity of the analytes. According to the manufacturer, the SPS pre-column contains internal and external stationary phases. The internal phase (inside the packing material pores) is a $\mathrm{C}_{18}$ phase that retains the hydrophobic analytes whereas the external phase (outside the packing material pores) is a hydrophilic polyoxyethylene that excludes the serum proteins through a combination of electrostatic repulsion and size exclusion. This design permits permeation of small analyte molecules to the internal stationary phase.

The mobile phase composition used for on-line sample extraction must not denature the serum proteins in the sample matrix. Generally, this means that the amount of organic solvent in the mobile phase should be limited to $15 \%$ or less (depending on the solvent). The aqueous portion of the mobile phase should contain a buffer with $\mathrm{pH}$ close to the physiological value. Furthermore, the mobile phase should have weak elution strength in order to retain the analytes on column. When the hydrophobic analytes interact with the $\mathrm{C}_{18}$ internal phase, they tend to be retained inside the packing material pores, allowing them to separate from the protein sample matrix.

In this work, both organic modifier and buffer concentration were optimized. Mobile phases for column-switching techniques are commonly based on phosphate buffer due to its compatibility with the biological matrix [17-21,26]. However, phosphate buffer is incompatible with ESI-MS detection; hence, $\mathrm{NH}_{4} \mathrm{Ac}$ buffer was used as the extraction buffer in this work. $\mathrm{CH}_{3} \mathrm{CN}$ was chosen as the organic modifier because it was also the major component of the mobile phase used for chiral separation on the analytical column. The $\mathrm{CH}_{3} \mathrm{CN}$ content was varied from 0 to $15 \%$ by the volume, and the $\mathrm{NH}_{4} \mathrm{Ac}$ concentrations of 0.05 and $0.1 \mathrm{M}$ at $\mathrm{pH} 6.98$ were tested. Our experiments indicated that higher content of $\mathrm{CH}_{3} \mathrm{CN}$ resulted in faster exclusion of the serum proteins from the SPS pre-column. However, at 15\% $\mathrm{CH}_{3} \mathrm{CN}$, an increased system pressure was observed indicating a partial denaturing of serum proteins on the pre-column. As compared with $0.1 \mathrm{M} \mathrm{NH}_{4} \mathrm{Ac}$ in $10 \% \mathrm{CH}_{3} \mathrm{CN}, 0.05 M \mathrm{NH}_{4} \mathrm{Ac}$ in $10 \% \mathrm{CH}_{3} \mathrm{CN}$ resulted in longer retention of the analytes, which is desirable for sample cleanup. Therefore, $0.05 \mathrm{M}$ $\mathrm{NH}_{4} \mathrm{Ac}$ at $\mathrm{pH} 6.98$ in $10 \% \mathrm{CH}_{3} \mathrm{CN}$ was used for as the mobile phase for the subsequent on-line sample cleanup.

The column-switching time is an important parameter in any on-line sample cleanup approach. If a premature switching time was used, the high organic content mobile phase used for chiral separation on the analytical column would denature remaining serum proteins in the pre-column and result in column clogging. In this work, the column-switching time was determined by the experiments shown in Fig. 3. Without the analytical column, the serum protein matrix eluted within $1 \mathrm{~min}$ and the analytes did not start to elute from the pre-column until 4.5 min using of $0.05 \mathrm{M} \mathrm{NH}_{4} \mathrm{Ac}(\mathrm{pH}$ 6.98) in $10 \%$ $\mathrm{CH}_{3} \mathrm{CN}$ as the mobile phase. Based on these results, the column-switching time for the subsequent analysis was chosen to be 4 min after sample injection 


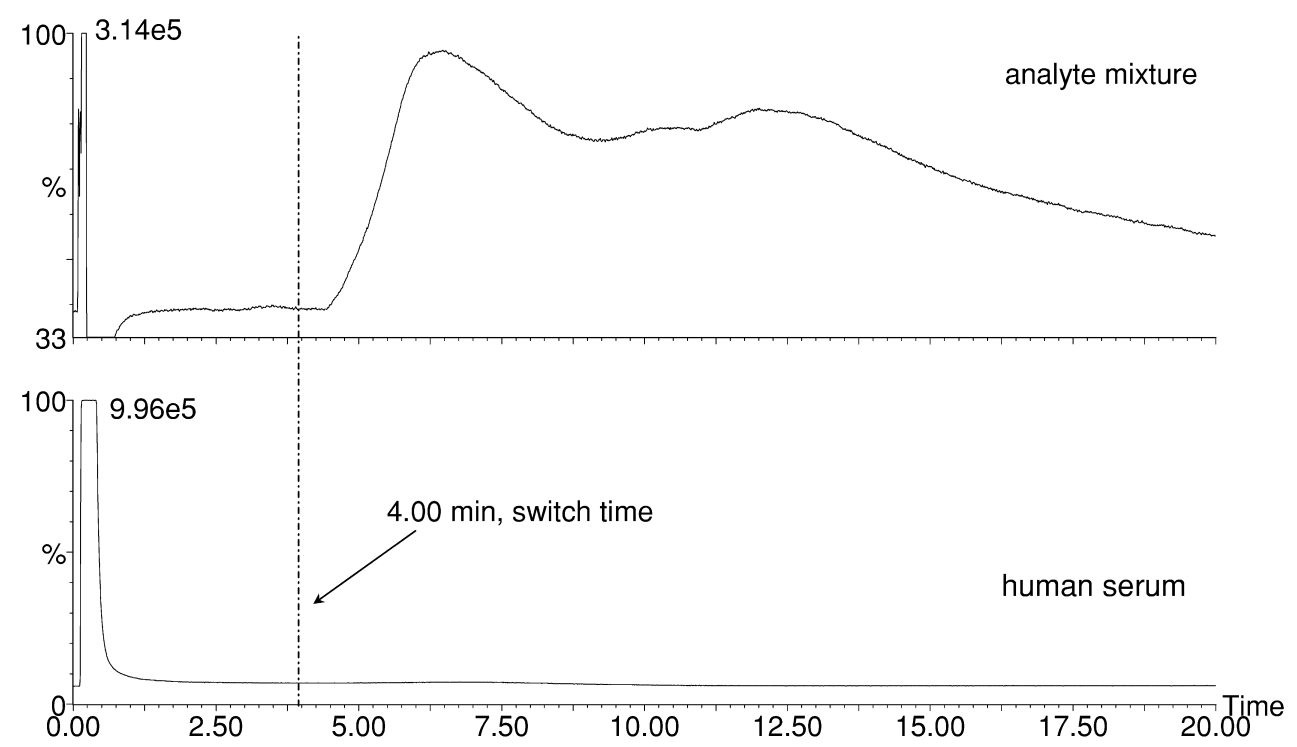

Fig. 3. UV chromatograms of analyte mixture (top trace) and control human serum (bottom trace). Analyte concentration, $126 \mu \mathrm{g} / \mathrm{ml} \mathrm{water}$ for each drug hydrochloride; instrumentation, the same as that shown in Fig. 2 without the $\beta$-CD column; UV detection at $258 \mathrm{~nm}$.

when the analytes still be retained on the SPS precolumn.

The effectiveness of the analytical column mobile phase for the elution of serum analytes from the SPS pre-column is shown in Fig. 4. In this experiment, $50-\mu 1$ samples were injected onto the SPS pre-column with the switching valve in the position A. At $4.0 \mathrm{~min}$, the system was switched to the position B, and the eluate from the pre-column was collected and analyzed by ESI-MS. Mass spectra of fractions collected during the 4-min time interval after the column switching showed that all analytes were present. Furthermore, there was no significant difference between peak intensities (as indicated by the intensity of the highest peak) of the corresponding analyte molecular peaks for the serum sample compared to the aqueous sample. This indicates that the analytical column mobile phase was indeed effective for eluting the analytes of interest from the precolumn regardless the presence of serum protein in the sample matrix (see Table 2 for the recoveries of each individual analyte). In this work, the analyticalcolumn mobile phase not only eluted the analytes from the SPS pre-column, but also cleaned the precolumn prior to the valve switching back to the position $\mathrm{B}$.

The column-switching system shown in Fig. 2 was tested in both "back-flush" and "forward-flush" mode. In the "back-flush" mode, the direction of flow of the chiral separation mobile phase through the pre-column is opposite to that of on-line sample cleanup. This approach is suitable for analytes that are strongly retained at the front portion of the pre-column. Better peak shapes may be obtained since analytes do not have to travel through the entire pre-column after the switching. The "forwardflush" mode is suitable for analytes that migrate further inside the pre-column during the sample cleanup step. In this work, the "forward-flush" mode was chosen because the column-switching time chosen was close to the initial elution of the analytes.

$$
L C-E S I-M S
$$

Due to the structural similarity between THP and other analytes in this work, a Cyclobond I 2000 native $\beta$-CD column [25] was chosen for their chiral separations. The separation conditions developed for THP enantiomers [25] were applied for the enantiomeric separation of procyclidine and biperiden with minor modification. In order to bring the retention times of procyclidine and biperiden to an acceptable level (less than $30 \mathrm{~min}$ ), the mobile phase composition was changed from previously reported 


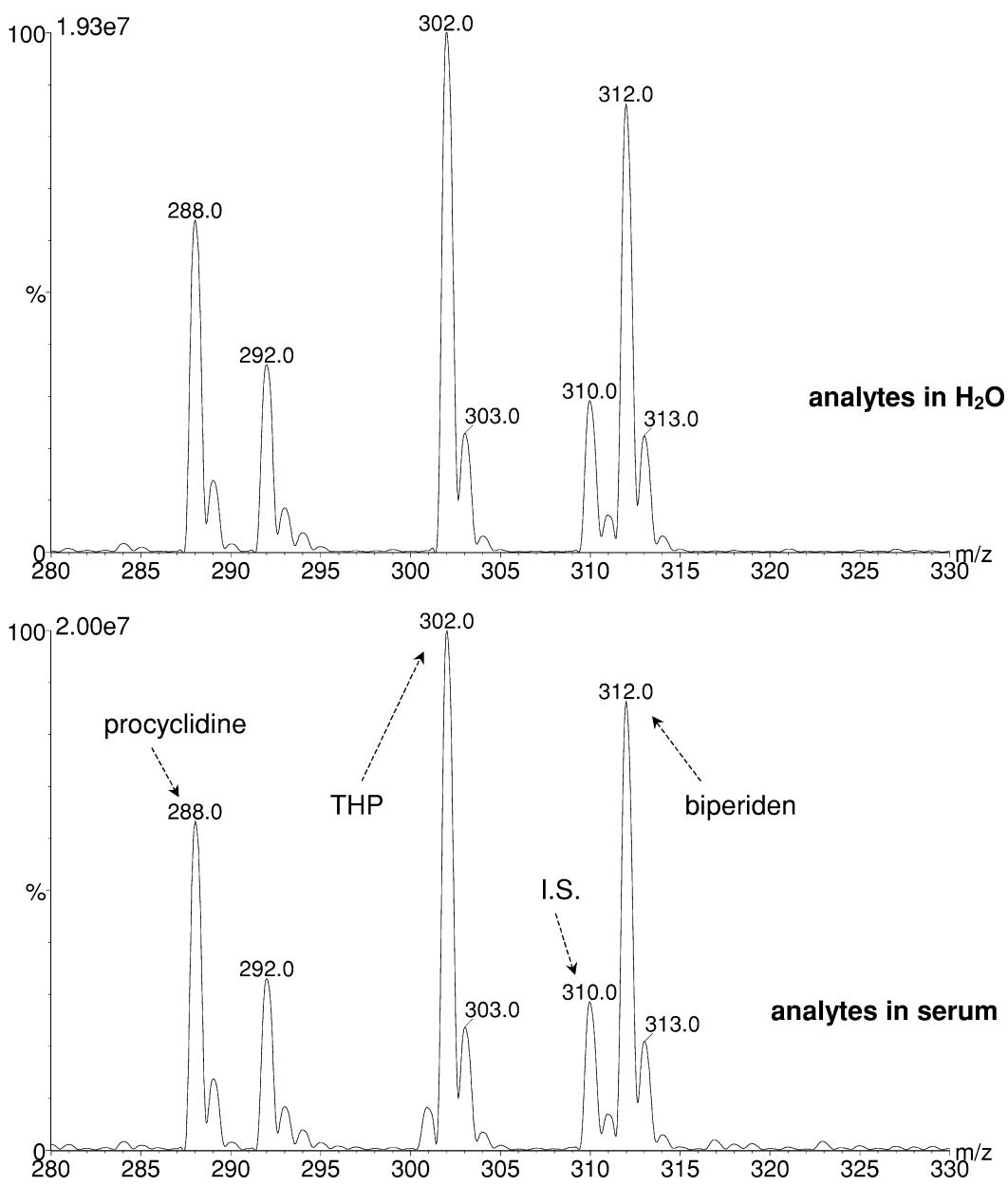

Fig. 4. Mass spectra of the elution fractions from the SPS pre-column after completion of sample extraction. Fractions collected during 4-min time interval starting at the time of switching; analyte concentrations, $170 \mu \mathrm{g} / \mathrm{ml}$ for THP. $\mathrm{HCl}, 167 \mu \mathrm{g} / \mathrm{ml} \mathrm{biberiden} \cdot \mathrm{HCl}$ and procyclidine $\cdot \mathrm{HCl}$, and $84 \mu \mathrm{g} / \mathrm{ml}$ for diphenidol $\cdot \mathrm{HCl}$.

$\mathrm{CH}_{3} \mathrm{CN}-\mathrm{CH}_{3} \mathrm{OH}-\mathrm{HAc}-\mathrm{TEA} \quad(95: 1: 0.5: 0.3, \quad \mathrm{v} / \mathrm{v})$ [25] to $\mathrm{CH}_{3} \mathrm{CN}-\mathrm{CH}_{3} \mathrm{OH}-\mathrm{HAc}-\mathrm{TEA}$ (95:5:0.5:0.3, $\mathrm{v} / \mathrm{v})$.

Fig. 5 shows the mass chromatograms of procyclidine, biperiden, THP and diphenidol (I.S.) acquired in both SIM, and MRM modes. In SIM mode, the quantitation ions were $\mathrm{m} / \mathrm{z}$ of 288,312 , 302 , and 310 for procyclidine, biperiden, THP and diphenidol, respectively. In MRM mode, the mass fragmentation reactions monitored were $288 \rightarrow 84$, $312 \rightarrow 98,302 \rightarrow 98$, and $310 \rightarrow 129$ for procyclidine, biperiden, THP and diphenidol, respectively. For all the parent ions, the maximal intensities of daughter ions were achieved at the collision energy of $20 \mathrm{eV}$.
As seen in Fig. 5, the signal-to-noise $(S / N)$ ratios in this work were greater in SIM mode than that in MRM mode, which were on the contrary to many LC-MS applications. Generally, even though MRM does not increase the analyte signals, it can eliminate most of the chemical background and result in an improved $S / N$ ratio. In SIM mode, the added selectivity of the third quadrupole is taken away; therefore, the $S / N$ ratio is usually smaller in SIM mode than that of MRM mode. The explanation of our observation come from the design of the Micromass Quattro II ESI triple-quadrupole MS. The instrument has two mass detectors, the first one located at the end of the first quadrupole and the second one 

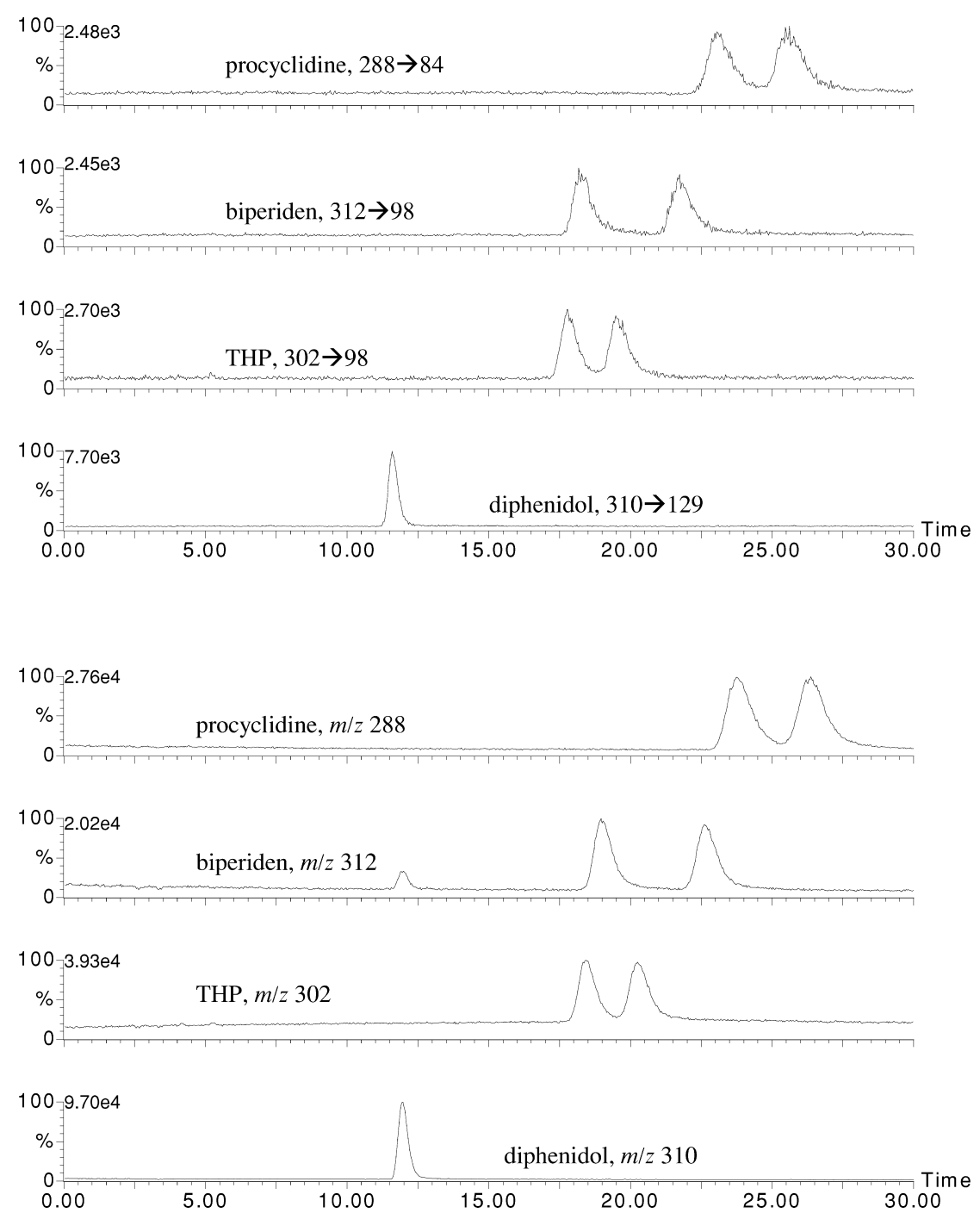

Fig. 5. LC-ESI-MS chromatograms of procyclidine, biperiden, THP, and diphenidol acquired in MRM mode (the top four traces) and in SIM mode (the bottom four traces). Analyte enantiomer concentrations, $50 \mathrm{ng} / \mathrm{ml}$ for each drug hydrochloride in the analytical column mobile phase.

behind the third quadrupole. Most ESI-MS-MS systems in use contain only one detector located behind the third quadrupole. When such a singledetector system is used, the partial loss of ions caused by ion transmissions from first to the second and third qudrupoles is compensated by a dramatic decrease of chemical background in MRM mode. Therefore, improved $S / N$ ratio is observed. However, in the case of two-detector system used in this work, the first detector was used for SIM mode, and the second detector was used for MRM mode. Consequently, the analyte ion trajectories in SIM mode were shorter than those in MRM mode, and the losses of ions due to collisions with the residual gas molecules during their transmission from the first to the third quadrupole were eliminated. Therefore, the $S / N$ ratios were greater in the SIM mode in our case.

The fact that the sensitivity gain due to the decrease of background in MRM mode did not 
outweigh the sensitivity gain caused by the shorter ion trajectory in SIM mode suggests that the background noise in Fig. 5 was of electronic rather than chemical nature. In this work, SIM mode was used for the final method validation. It is worth noting that in the case of insufficient sample cleanup, the chemical noise can outweigh the electronic one, and the MRM mode may be more appropriate for quantitation (so as in the case of single-detector MS-MS system).

\section{Analytical performance}

Quantitative analysis of THP, procyclidine and biperiden was carried out using diphenidol as an internal standard. Diphenidol is an achiral antiemetic drug structurally similar to the analytes (Fig. 1). Prior to the analysis, the internal standard was added to the serum samples containing analytes. The serum samples were then cleaned-up on-line and analyzed by LC-ESI-MS in the SIM mode. A representative chromatogram of serum sample is shown in Fig. 6. All drug enantiomers were stereochemically resolved. Although these drugs were not completely time-resolved from each other due to their structural similarity, they were readily quantified by exploiting the mass selectivity of the SIM mode of ESI-MS detection.

According to Desage et al. [1], the maximal therapeutic plasma concentration of THP after a single 15-mg dose was $55 \mathrm{ng} / \mathrm{ml}$. Postmortem THP concentrations after a $20-\mathrm{mg}$ oral dose were found to be as high as $380 \mathrm{ng} / \mathrm{ml}$ in urine [27]. For biperiden, a 20-mg dose can produce blood concentration levels approximately $50 \mathrm{ng} / \mathrm{ml}$ [27]. In the case of procyclidine, the steady state blood concentrations of $150-630 \mathrm{ng} / \mathrm{ml}$ were reported. In overdosing and drug abuse, the postmortem procyclidine concentrations of $4-4.4 \mu \mathrm{g} / \mathrm{ml}$ in blood, $11-15 \mu \mathrm{g} / \mathrm{ml}$ in liver, and $1.8-7 \mu \mathrm{g} / \mathrm{ml}$ in urine were previously reported [27]. It should be pointed out that some of these concentration levels were determined after a single oral dose of drug was administered. The steady-state concentrations of these drugs would be higher.

Table 1 shows the regression parameters of internal calibrations for THP, biperiden and procyclidine enantiomers. As indicated by the correlation co-
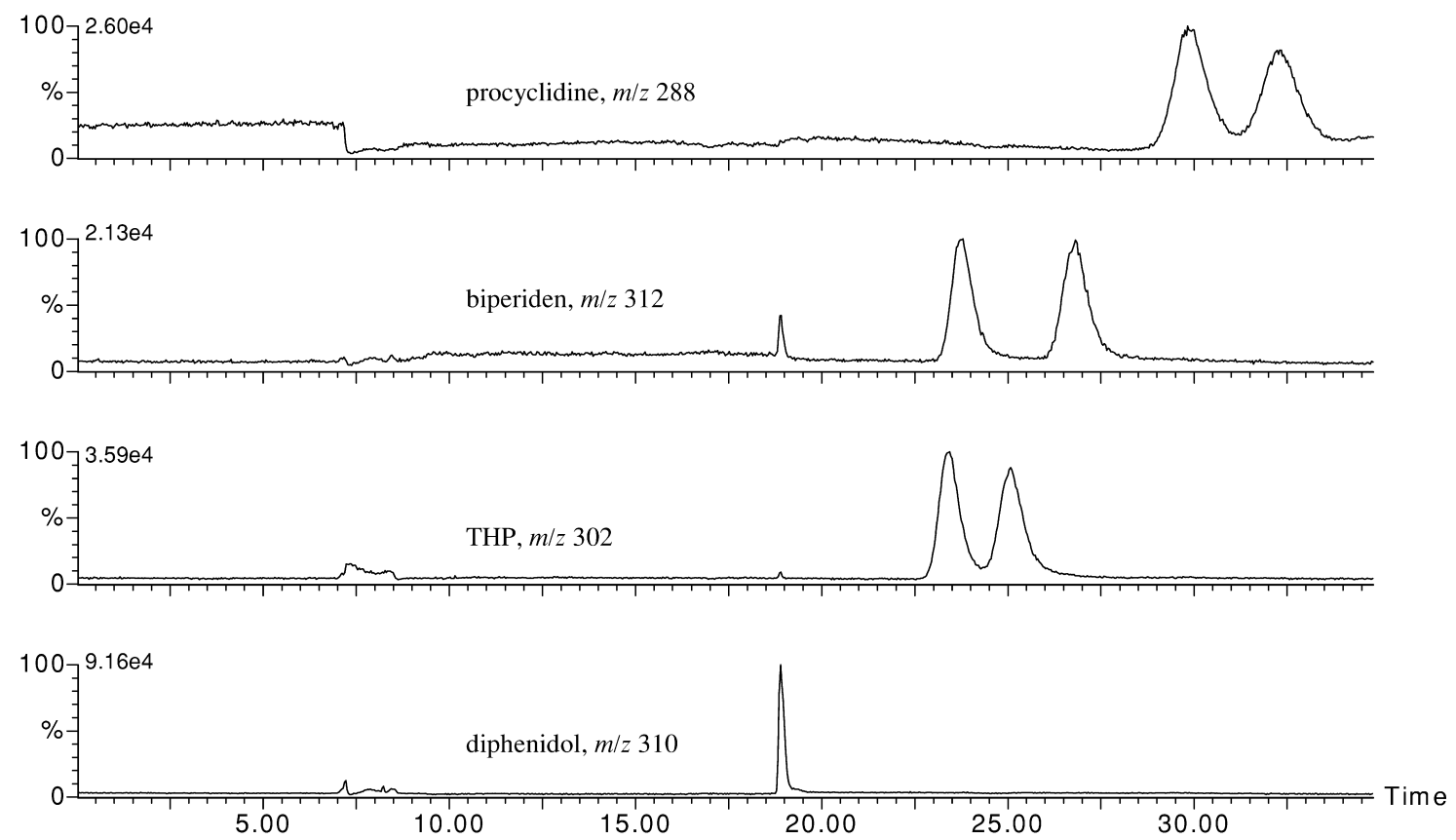

Fig. 6. A representative LC-ESI-MS chromatogram of serum sample. Analyte enantiomer concentration, $50 \mathrm{ng} / \mathrm{ml} \mathrm{in}$ serum for each drug hydrochloride. 
Table 1

Regression parameters of internal calibration curves for enantiomers of THP, biperiden and procyclidine $(n=6$; confidence level=95\%; calibration range: $11-600 \mathrm{ng} / \mathrm{ml}$ )

\begin{tabular}{llll}
\hline Compound & & Regression equation & Correlation coefficient \\
\hline THP & First peak & $y=0.0167\left( \pm 2.4 \cdot 10^{-4}\right) x-0.005( \pm 0.064)$ & 0.9996 \\
& Second peak & $y=0.0157\left( \pm 2.4 \cdot 10^{-4}\right) x+0.006( \pm 0.062)$ & 0.9996 \\
Biperiden & First peak & $y=0.0095\left( \pm 6.5 \cdot 10^{-5}\right) x-0.000( \pm 0.017)$ & 0.9999 \\
& Second peak & $y=0.0082\left( \pm 1.1 \cdot 10^{-4}\right) x-0.007( \pm 0.029)$ & 0.9996 \\
Procyclidine & First peak & $y=0.0146\left( \pm 9.1 \cdot 10^{-5}\right) x+0.010( \pm 0.024)$ & 0.9999 \\
& Second peak & $y=0.0126\left( \pm 8.1 \cdot 10^{-5}\right) x-0.001( \pm 0.021)$ & 0.9999 \\
\hline
\end{tabular}

efficients $(\geq 0.9996)$, the method shows excellent linearity within the calibration ranges of 11-600 $\mathrm{ng} / \mathrm{ml}$. In fact, the linearity of the method was evaluated up to $1140 \mathrm{ng} / \mathrm{ml}$ and the calibration curves still showed good correlation coefficients $(>0.99)$. The detection limits of the method (defined as concentration at $S / N=3$ ) were determined to be 1 $\mathrm{ng} / \mathrm{ml}$. The detection limits may be further improved by injecting larger sample volumes onto the SPS pre-column. Injection volumes up to $500 \mu \mathrm{l}$ were reported with some "restricted access media" without significant band broadening [18,19,21]. According to the aforementioned studies $[18,19,21]$, total plasma volume of $50 \mathrm{ml}$ or more could be injected onto the pre-column. If large sample volume is applied, more frequent replacement of the SPS precolumn is needed. This is consistent with our observations with the SPS pre-column. Detection limits may also be improved by use of microbore column (i.e., $1.0 \mathrm{~mm}$ I.D.) for chiral separation because of its compatible flow-rate, low void volume and high separation efficiency.

Recovery studies of THP, biperiden, procyclidine, and internal standard were carried out by injecting both serum and aqueous standards into the on-line
SPE and LC-ESI-MS system. The results shown in Table 2 were obtained by comparing the peak areas of a serum standard with the corresponding peak areas of an aqueous standard at the same concentration level. These results showed that the absolute recoveries ranged $98.4-100.4 \%$ with relative standard deviations (RSDs) of $2.2-8.6 \%$. The recoveries indicated that the compounds being studied either did not bind to serum proteins or their binding to serum proteins was disrupted by the SPS pre-column. Hypothetically, the binding of drug to serum proteins is governed by chemical equilibrium. When the serum sample containing drug molecule is loaded onto the SPS pre-column, the unbound drug partitions in the hydrophobic internal stationary phase whereas the protein-bound drug resides in the mobile phase because of the exclusion of the large protein molecules from the packing material pores. New equilibrium between the bound and unbound drug molecules follows the addition of fresh eluent that carry the drug molecules to the next portion of the "naked" stationary phase. In accordance with their distribution coefficients, the unbound drug again resides in the hydrophobic internal stationary phase and the bound drug in the mobile phase. As the

Table 2

Absolute recoveries of diphenidol, THP, biperiden and procyclidine from human serum

\begin{tabular}{lclll}
\hline & \multicolumn{2}{c}{$\%$ Absolute recovery } & & \\
\cline { 2 - 5 } & First peak & RSD $(\%)$ & Second peak & \\
\hline Diphenidol (I.S.) & 98.4 & 7.3 & 101.4 & 3.4 \\
THP & 100.1 & 7.6 & 101.3 & 2.2 \\
Biperiden & 99.8 & 4.9 & 100.4 & 6.7 \\
Procyclidine & 100.4 & 8.5 & & \\
\hline
\end{tabular}

Analyte enantiomer concentrations, $50 \mathrm{ng} / \mathrm{ml}$ each drug hydrochloride, $n=3$. 
Table 3

Intra- and inter-assay reproducibility data $(n=6)$

\begin{tabular}{|c|c|c|c|c|c|c|c|c|}
\hline & \multicolumn{4}{|l|}{ Intra-assay } & \multicolumn{4}{|l|}{ Inter-assay } \\
\hline & First peak & $\operatorname{RSD}(\%)$ & Second peak & $\operatorname{RSD}(\%)$ & First peak & $\operatorname{RSD}(\%)$ & Second peak & $\operatorname{RSD}(\%)$ \\
\hline THP/I.S. & $0.79 \pm 0.07$ & 6.4 & $0.75 \pm 0.04$ & 4.4 & $0.81 \pm 0.08$ & 8.8 & $0.73 \pm 0.08$ & 8.6 \\
\hline Biperiden/I.S. & $0.38 \pm 0.03$ & 8.8 & $0.34 \pm 0.03$ & 7.5 & $0.36 \pm 0.03$ & 9.7 & $0.33 \pm 0.03$ & 10.6 \\
\hline Procyclidine/I.S. & $1.08 \pm 0.05$ & 4.5 & $0.94 \pm 0.06$ & 6.2 & $1.03 \pm 0.08$ & 8.1 & $0.93 \pm 0.05^{\mathrm{a}}$ & $5.5^{\mathrm{a}}$ \\
\hline
\end{tabular}

${ }^{\mathrm{a}} n=5$.

result of this ongoing process, the protein-bound drug can be released and drug-free serum proteins can be excluded from the SPS pre-column. This hypothesis was previously studied by Hermansson et al. [20,21] and their data along with the recovery data of our previous work [25] supported the theory.

The intra- and inter-assay reproducibilities of the method were evaluated and the data are shown in Table 3. The intra-assay reproducibility was studied by multiple injections of the same sample; whereas the inter-assay reproducibility was based on the injections of identically prepared samples. The results showed that the RSDs of all enantiomers were $\leq 8.8 \%$ (except for one case where the RSD was $10.6 \%$ ). The good reproducibility might be attributed to the minimal sample handling.

The method developed can be easily automated by replacing the manual Rheodyne 7000 two-position six-port switching valve with a commercially available electronic switching valve. The system operation can be streamlined to increase sample throughput. After initial sample injection, the subsequent on-line sample extractions and analytical separations can be conducted in parallel. For example, $15 \mathrm{~min}$ after the initial injection, the switching valve can be switched back from position $\mathrm{B}$ to position $\mathrm{A}$, and the second sample can be extracted before the first analytical separation is completed. Consequently, the total run-time can be shortened.

\section{Conclusions}

A simple and quantitative LC-MS method for the determination of enantiomers of THP, biperiden and procyclidine in human serum has been developed. The method has a wide dynamic range, low detection limits, good reproducibility, and excellent recovery.
It is well suited for clinical, toxicological, and pharmacological analyses where the simultaneous analysis of the above compounds is needed. The method uses on-line sample extraction that replaces the conventional time-consuming sample preparations. The method can be easily automated for increased sample throughput and unattended analyses.

\section{Acknowledgements}

This work was supported by the University Graduate Council of the Cleveland State University. The authors are grateful to the Knoll Pharmaceutical Company for the generous donation of biperiden standard.

\section{References}

[1] M. Desage, M. Rousseau-Tsanngaris, D. Lecompte, J.L. Brazier, J. Chromatogr. 571 (1991) 250.

[2] J.A. Owen, M. Sribney, J.S. Lawson, N. Delva, F.J.J. Letemendia, J. Chromatogr. 494 (1989) 135.

[3] K. Dean, G. Land, A. Bye, J. Chromatogr. 221 (1980) 408.

[4] P. Ottoila, J. Taskinen, J. Chromatogr. 226 (1981) 488.

[5] P. Knitz, B. Godelar, P. Mangin, A.J. Chaumont, J. Anal. Toxicol. 13 (1989) 47.

[6] W.D. Glanze, K.N. Anderson, L.E. Anderson, Mosby's Medical Dictionary, 4th ed., Mosby, St. Louis, MO, 1994.

[7] M. Waelbroeck, M. Tastenoy, J. Camus, R. Feifel, E. Mutschler, C. Strohmann, R. Tacke, G. Lambrecht, J. Christophe, Trends Pharmacol. Sci. 10 (Suppl. IV) (1989) 65.

[8] G. Blaschke, H.P. Kraft, H. Markgraf, Chem. Ber. 113 (1980) 2318.

[9] P. Onali, A.J. Aasen, K. Olianas, Br. J. Pharmacol. 113 (1994) 775. 
[10] M. Waelbroeck, J. Camus, M. Tastenoy, E. Mutschler, C. Strohmann, R. Tacke, L. Schjelderup, A. Aasen, G. Lambrecht, J. Christophe, Eur. J. Pharmacol.-Mol. Pharmacol. Sect. 227 (1992) 33.

[11] F. Dorje, J. Wess, G. Lambrecht, R. Tacke, E. Mutschler, M.R. Brann, J. Pharmacol. Exp. Ther. 256 (1990) 727.

[12] G. Lambrecht, R. Feifel, U. Moser, A.J. Aasen, M. Waelbroeck, J. Christophe, E. Mutschler, Eur. J. Pharmacol. 155 (1988) 167.

[13] R. Tacke, H. Linoh, D. Schomburg, L. Ernst, U. Moser, E. Mutschler, G. Lambrecht, Liebigs Ann. Chem. 2 (1986) 242.

[14] R.B. Barlow, D. Dawbarn, C.J. Pycock, Br. J. Pharmacol. 72 (1981) 277.

[15] R.B. Barlow, J. Pharm. Pharmacol. 23 (1971) 90.

[16] M. Eltze, V. Figala, Eur. J. Pharamacol. 158 (1988) 11.

[17] A. Rudolphi, K.-S. Boos, LC·GC 15 (1997) 814.

[18] Z. Yu, D. Westerlund, J. Chromatogr. A 725 (1996) 137.
[19] Z. Yu, D. Westerlund, J. Chromatogr. A 725 (1996) 149.

[20] J. Hermansson, A. Grahn, J. Chromatogr. A 660 (1994) 119.

[21] J. Hermansson, A. Grahn, I. Hermansson, J. Chromatogr. A 797 (1998) 251.

[22] R. Oertel, K. Richter, T. Gramatté, W. Kirch, J. Chromatogr. A 797 (1998) 203.

[23] P. Önnerfjord, D. Barceló, J. Emnéus, L. Gorton, G. MarkoVarga, J. Chromatogr. A 737 (1996) 35.

[24] E.A. Hogendoorn, P. van Zoonen, A. Polettini, G.M. Bouland, M. Montagna, Anal. Chem. 70 (1998) 1362.

[25] V. Čápka, Y. Xu, J.-H. Chen, J. Pharm. Biomed. Anal. 21 (1999) 507.

[26] J. Haginaka, J. Wakai, Anal. Chem. 62 (1990) 997.

[27] A.C. Moffat, J.V. Jackson, M.S. Moss, B. Widdop, Clarke's Isolation and Identification of Drugs in Pharmaceuticals, Body Fluids, and Post-Mortem Material, 2nd ed., Pharmaceutical Press, London, 1986. 